\title{
Resisting, Reaching Out and Re-imagining to Independence: LPN's Transitioning towards BNs and Beyond
}

\begin{abstract}
Little is known about the process of how nurses transition between vocational training and institutions of higher education. Understanding this process provides educators with the knowledge to support new groups of university students making this transition. Grounded theory (GT) was used to explore and understand this process. Three studies from a 7-year research program were used as data. The analysis led to the generation of a GT illuminating the process of students transitioning from post-LPN to BN. This GT illustrates how students overcome difficulties encountered moving to a more complex nursing role. The students' main concern was a lack of independence. The core variable, which resolves this main concern, and which emerged from the analysis of the data is developing independence. There are three sub-core variables, resisting, reaching out and re-imagining which support this core variable of developing independence.
\end{abstract}

Keywords: LPN to BN learning, independence, grounded theory

*Corresponding author: Sherri Melrose, Athabasca University, 1 University Dr, Athabasca, AB T9S 3A3, Canada,

E-mail: sherrim@athabascau.ca

Paul M. Wishart, University of Calgary, 2500 University Dr NW, Calgary, AB T2N 1N4, Canada, E-mail: pmwishart@shaw.ca

Licensed practical nurses (LPN) have usually earned their nursing credential in vocational institutions and are seldom awarded recognition in university bachelor of nursing (BN) degree programs for their prior learning. Vocational programs focus on procedural knowledge and occupation-specific training, whereas universities focus on conceptual knowledge and theoretical understanding (Karmel, 2011). Some registered nurse (RN) programs at community colleges offer LPN to RN diploma bridging programs and acknowledge the LPN credential. In most Canadian provinces, RNs are required to complete a university nursing degree. More opportunities for LPNs to transition to RNs are becoming available, but the literature addressing their experiences is mainly descriptive. A deeper theoretical understanding of the transitioning process these nurses follow, their concerns and the strategies they use to resolve them is needed. To address this lack of understanding, three studies from a 7-year program of research were used as data for a grounded theory (GT) analysis.

\section{Background}

In Canada, nursing education opportunities are available in vocational, college and higher education institutions. The majority of entry-level nursing students earn an LPN credential from a 2-year program or a BN degree from a 4-year university program. When credit for prior learning is awarded, LPN students may be able to earn a BN degree in 2 years. With the exception of the post-LPN to $\mathrm{BN}$ group, students awarded credit for prior learning have previous exposure to the demands of university. However, nurses who transition from one post-secondary system to another and have to adjust to the university system face unique challenges.

Making the transition from vocational training to university programs is not easy. Sharp differences exist. In school, students are often selected at an early age for either a vocational or an academic track (Moodie, 2008). Named "the Cinderella of tertiary education," vocational education continues to be viewed by some as a second, less glamorous post-secondary educational choice (Institutional Management in Higher Education [IMHE], 2012, p. 1). Despite international efforts to promote vocational education, "parity of esteem between vocational and academic qualifications remains a myth" (Hayward, Dunbar-Goddet, Ertl, \& Hoelscher, 2008, p. 1). Consequently, determining equivalence between qualifications among vocational programs is difficult and in turn also makes awarding credit for prior learning 
difficult (Hoelscher, Hayward, Ertl, \& Dunbar-Goddet, 2008; Langworthy \& Johns, 2012; Moodie, 2008).

Generally, students transitioning between post-secondary institutions can expect to face challenges. Vocational programs are more likely to provide considerable individual guidance and encourage instrumentality, making the more anonymous impersonal university environment difficult to comprehend (Crabtree, Roberts, \& Tyler, 2007). Students in a Faculty of Business who upgraded from vocational training to an institution of higher education were unaware that independent learning was a requirement for success in higher education. They also lacked many of the skills necessary for effective independent study (Crabtree et al., 2007). College-prepared Social Work students found that the transition to a research-led university was not easy (Cree, Hounsell, Christie, McCune, \& Tett, 2009). Students at five different universities transitioning from vocational training programs experienced difficulties understanding expectations of them, particularly in the areas of essay writing and mathematics (Hayward et al., 2008).

LPNs transitioning between institutions face unique challenges. LPNs may enter RN programs with unrealistic expectations regarding program rigor and flexibility (Brown, 2005). Often, they feel shocked by the magnitude of work (Claywell, 2003), which may lead to struggles assimilating into the academic learning environment (Hutchinson, Mitchell, \& St John, 2011). Previous learning experiences may not have prepared them for RN level study (Hylton, 2005). They struggle to overcome role ambiguity (Cubit \& Leeson, 2009) and grapple with their dual identity (Hutchinson et al., 2011). Some find the working role of an $\mathrm{RN}$ is more complex, broad and mentally and physically trying than expected (Kilstof \& Rochester, 2004). They may experience a cultural transition requiring they question traditionally held values and adopt a more critical stance to their professional practice (Milligan, 2007). Arranging employment leaves and travel away from home to complete practica is often problematic (Rapley, Nathan, \& Davidson, 2006). In some instances, post-LPN to BN students found they had to terminate their full time employment to continue their studies (Melrose \& Gordon, 2011). Students described how expectations placed on them by clinicians and managers exceeded their level of expertise, resulting in increased levels of anxiety (Nayda \& Cheri, 2008). They may even associate gains from their new university education with some loss of their hands on bedside nursing role (Melrose \& Gordon, 2008).

A final challenge, unique to this group of nurses, is the apparent task similarity that exists within both the LPN and RN roles. Appreciating differences between LPN and RN responsibilities is complex. Both groups study similar foundational knowledge, are governed by regulatory colleges and are guided by distinct standards. However, RNs study longer, have a wider, more indepth scope of practice and earn higher salaries. In most instances, LPNs collect client data and report findings, while RNs synthesize the data and make independent decisions (Kearney-Nunnery, 2010). Workplace policies differ significantly: LPN tasks often focus on collecting quantifiable data such as vital signs; RNs incorporate data into more holistic assessments, coordinate care and identify the need for involvement of other health professionals (White et al., 2008).

Although both LPNs and RNs strive to provide exemplary care to their clients and nursing leaders strive to deploy all nurses efficiently (Harris \& McGillis Hall, 2012), relationships between the two groups can be strained. LPN's may feel that they are not respected, that their nursing knowledge as LPN's is not acknowledged and that they are undervalued within the RN community (Melrose \& Gordon, 2008). LPNs invest considerable emotional labor into their interactions with RNs. This investment often goes unrecognized (Huynh, Alderson, Nadon, \& Kershaw-Rousseau, 2011). Over the past decade, with LPN programs lengthening, the scope of practice increasing and the patient care tasks they implement seeming very similar, LPNs often view the two roles as interchangeable (Huynh et al., 2011).

\section{The research approach}

This study investigated the experiences of post-LPN nurses transitioning to BN students to understand how post-LPN nurses overcome difficulties associated with the transition from vocational to institutions of higher education and learning a more complex nursing role. Classic GT (Glaser, 1978, 1992, 1998; Glaser \& Strauss, 1967) was used for the analysis. Two key components of the methodology of GT were emphasized, constant comparison and memoing, to maximize the probability of generating theory that is relevant to the action in the area studied (Glaser, 1978). Constant comparison and memoing facilitate and cultivate conceptualization and emergence of a relevant GT of what is going on in the data.

\section{Data collection}

Three studies that formed part of a 7-year research program were used as data. Participants were all students in 
a post-LPN to BN program at a Canadian university. In the first study, from 2006 to 2009, 10 students were individually interviewed three times: at the beginning (Melrose \& Gordon, 2008), middle (Melrose \& Gordon, 2011) and end or post-graduation (Gordon \& Melrose, 2011a) of their program. These 30 interviews provided snapshots of how their views changed and remained the same.

In the second study, from 2010 to 2011, 27 students participated in four focus groups held in different geographic locations (Melrose, Miller, Gordon, \& Janzen, 2012). The focus groups were held during non-course hours when students were completing clinical practica on acute medical-surgical hospital units.

In the third study, in 2011, 16 students podcast audio messages of encouragement to their peers (Gordon \& Melrose, 2011b). Students were invited to leave telephone messages sharing strategies that worked for them, as they faced the challenges of attending university and learning a more complex nursing role. The collection of messages added important insight to theory generation as students commented on the practical ways they resolved the everyday problems they encountered. This provided information on the difficulties they encountered and how they were resolved.

Separately, in each of these three descriptive studies, ethical approval was obtained from the university; new participants were recruited and new researchers were added to the team. None of the researchers had teaching responsibilities in the post-LPN to BN program. In these previous studies, data (transcripts of recorded interviews, focus groups or telephone messages) were analyzed using line by line coding to create categories that led to themes. In the present study, GT was used to conceptualize, link and extend the cumulative data from the studies.

\section{Data analysis}

Constant comparison and memoing were emphasized in the data analysis to facilitate the generation of GT, illuminating the transition process of post-LPN to BN students. Interview, focus group and telephone message data previously analyzed and presented at a descriptive level were re-analyzed using GT. Applying GT moved the analysis beyond the descriptive to understand and conceptualize the transition process. New concepts and categories emerged which upon constant comparison and memoing, led to the identification of the main concern of the participants, and the core variable, how this main concern of the participants in the study was being resolved.

The theory generated was evaluated using Glaser's $(1978,2001)$ criteria for a generated GT. These criteria are that the theory must be relevant. It also must grab, fit and work with the data from which it was derived. Lastly, the theory is modifiable. The theory transcends a descriptive focus on individuals to generate the process of nurses transitioning between vocational and institutions of higher education. Generating this GT increases resonance with learners who are making transitions. The theory illustrates how students overcame difficulties they encountered moving to their more complex nursing roles.

\section{The theory}

The students' main concern was a lack of independence. The core variable, which resolves this main concern, emerged from the analysis of the data. The core variable is developing independence. Three sub-core variables supporting this process of developing independence were resisting, reaching out and re-imagining. The process of developing independence and the three sub-core variables supporting nurses' developing independence are illustrated in Figure 1.

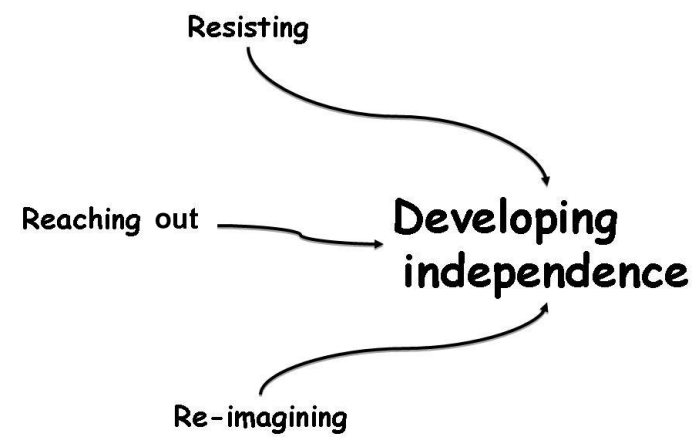

Figure 1 Resisting, reaching out and re-imagining to independence.

\section{Findings}

\section{Resisting}

I'm a nurse already - what's new? Throughout all three studies, post-LPN to BN students emphasized that they were "already nurses." They consistently resisted the notion that they were "becoming" nurses or being "socialized into" the nursing profession. Many felt 
"insulted" when others posed questions such as "when will you finish and be a nurse?" When researchers referred to the post-LPN to BN program as "upgrading education," one nurse adamantly explained that this term was pejorative and urged us to say "continuing education" instead. Participants repeatedly expressed how they saw little or no difference between the LPN and RN roles. Comments such "we already think critically" and "we do the same things - RNs are just paid more" were common, particularly in the beginning and middle individual interviews and in the focus group discussions. LPNs were proud of the nursing knowledge they already had but expressed that "RNs always have more authority."

Our participants often told us that they did not feel respected in their LPN role and this lack of respect was a key motivator in their decision to earn their RN credential. They shared workplace incidents where their knowledge as LPN's was not valued or even acknowledged. For example, one participant described how she was required to remain outside the door of a multidisciplinary conference while an RN presented client data this participant had collected and "written up." Another participant spoke about how "just LPNs" can be "good enough" when RNs were not available to "desperate" employers. In two of the focus groups, students discussed how "RN stands for Real Nurse and LPN stands for Little Pretend Nurse." These perceptions of being disrespected, devalued and excluded from the nursing community persisted as they completed courses and practica in their post-LPN to $\mathrm{BN}$ program.

Hurting: Seems I'm leaving bedside nursing behind this hurts! We heard considerable hurt and expressions of loss in the nurses' voices as they discussed leaving their role as LPN. In an early interview, a participant expressed how she viewed the RN role as "sitting behind the desk" while the LPN role involved "looking after patients at the bedside." Despite their comments explaining the inherent limitations of the role, LPNs loved the hands-on connections with patients their role provided. They did not want to abandon bedside nursing, remaining protective of their LPN credential throughout their program, even after they graduated. Relating an incident that occurred during an interview for a new job as an RN, a participant wondered why the employer required her to "choose between LPN and RN on my nametag - I want both on there." Knowing that these feelings of hurt and abandonment are occurring within the transition process, it is not surprising that post-LPN to BN students respond with resistance.

\section{Reaching out}

Am I doing OK? During their practica on acute hospital units, many LPN to BN students still did not recognize the significant differences between the LPN and RN role. However, most became less resistant and more open to actively seeking answers from others when they reached the point in their program where they attended clinical sites. Students did not see themselves as "doing anything differently"; it was others' affirmations that they were that made a difference. When workplace or practica mentors shared how students thinking or actions "fit" the RN role more than the LPN role, this feedback legitimized their learning and indicated that change was actually happening.

As students risked letting go of their resistance and began tentatively reaching out for help, feedback from instructors and preceptors was strikingly important. For example, one participant "kept every set of comments I've ever gotten from preceptors and instructors." Another tearfully recounted a failed clinical experience. Although nearly 2 years had passed since this failure, she remained deeply affected by the feedback. She responded to the challenge of failing by repeating the course and seeking out evaluators who "did know I'm a good nurse."

Sacrificing: Sold my home, gave up my job - Costs are more than money. Post-LPN to BN students made substantial sacrifices to continue their education. Two participants told us they had sold their homes to pay for their program. Of the ten students interviewed at the beginning, middle and end or post-graduation, five had either terminated their full time employment or changed to jobs with reduced hours to attend practica and finish their degrees. Focus group discussions frequently included comments related to giving up time with family and friends.

The telephone messages of encouragement participants shared with peers centered on strategies to reduce stress, manage time more efficiently and persist "no matter what." As these nurses "put life on hold," they expected academic and clinical learning events that would make these sacrifices "worthwhile."

Challenges occurred when learning events did not seem worthwhile or when instructors and preceptors did not seem to understand the depth of their sacrifice. In the words of one participant: "the costs are more than money." Another commented angrily on how one university course "had the same textbook" used in her LPN program. In her practicum, a participant felt frustrated when she was "buddied with an LPN when I'm supposed 
to be learning to be an RN." Comments about not wanting to "waste time and tuition money to work on a unit I'd get paid to work on as an LPN" were common.

In order for the post-LPN to BN students to resolve these difficulties and become more independent, they needed help from others. Unfortunately, when they communicated their feelings of frustration and anger with the intention of reaching out for help, they found their intentions were misunderstood and they were viewed as "complaining." Time and again our participants iterated how valuable it was that others could see and would respond when they were reaching out for the help and direction they needed.

\section{Re-imagining}

I see the difference now - I want to lead with this new vision. Two years after graduating from her program, one participant discussed how she views the RN role very differently now. She spoke about how her thinking changed, how her perspective shifted and how she gained "a new depth of knowledge," particularly once she was employed as an RN. When this same participant was previously interviewed during the middle of her program, she commented on her belief that "LPNs could work in speciality areas - they have as much to offer as RN's." But, when the interviewer revisited this comment in her final interview, she no longer felt it was true. She continued to champion LPN nurses, but "when it comes to the difference between the roles, you don't really know until you get there." Reflecting on what stood out for her most during her transition from LPN to $\mathrm{RN}$, she reported how much more "confident and comfortable" she felt both personally and professionally. She shared how the ritual of clasping her $\mathrm{RN}$ pin to her uniform was very meaningful. This action reminded her that she "used to feel that maybe I'm not correct - maybe I'm wrong. But as an RN, I have more confidence. When people look at this pin, I feel I do get more respect.” Like this participant, as other post-LPN to BN students and graduates began to feel more confident and respected in their new role, they also began to re-imagine how they could contribute to their profession. In their telephone messages of encouragement, students urged peers to participate in the professional development activities now becoming available to them. Suggestions such as "try joining committees or projects that are going on - as RNs we can" were made. A process of re-imagining professional possibilities subtly took on greater importance than resisting the idea that differences between the roles existed. Similarly, as the nurses cautiously began envisioning themselves in their new nursing role, they had less need to reach out for affirming feedback from others. One focus group participant named this process "nurse life changing." When the nurses began their transition to a new and more complex nursing role, they were motivated in part by a desire to move beyond the dependencies associated with the LPN role. They shared ideas about how they could support other LPNs to continue their education and how as RNs, they could now become leaders initiating meaningful change.

\section{Core variable: developing independence}

I'm no longer in someone's shadow. Developing independence is the core variable for post-LPN to BN students as they transitioned towards the more complex nursing role of an RN. Both during their program and beyond their formal studies, this group of nurses struggled towards developing independence. As LPNs, they were required to collect and report data rather than make significant client care decisions. As vocational students, they were provided more instrumental guidance than opportunities for self-direction. Although they viewed themselves as an integral part of the professional nursing community, they often felt disrespected and excluded by RNs. At the outset of their transition, they saw little difference between the LPN and RN role, and many entered their university program without previous university experience.

\section{Discussion}

The process and strategies that learners undertake to develop and support independence as RNs are inherently difficult to understand, yet university programs consistently expect and require students to think and act independently. A key element in developing independence in any educational activity is for students to take responsibility for their learning above and beyond responding to instructions (Boud, 1988; Knowles, 1975). Becoming independent requires students to choose fitting learning activities, reflect on their effectiveness and initiate any needed changes (Holec, 1981; Little, 1991).

Vygotsky's (1978) seminal term "zone of proximal development" is the "distance between the actual development level as determined by independent problem solving and the level of potential development as determined through problem solving under ... guidance” (p. 86). In 
essence, this developmental zone encompasses the discrepancies between what learners can accomplish with support and what they can accomplish independently. PostLPN to BN learners with limited previous university experience enter their program with a wide zone of proximal development, and they require considerable guidance and support before they can achieve independence.

Unrelenting expectations of independence associated with their new role was the main concern this group of adult learners encountered. Given that LPNs have consistently been denied opportunities to venture beyond responding to direction from others, the challenge of developing their independence becomes clear. Developing independence, the core variable, is supported by a spiralling process of resisting, reaching out and re-imagining.

Resisting the idea that differences actually existed between the roles helped narrow the gap between what they already knew and what they still needed to learn. Reaching out for help and affirmation that what they were doing was on track was a familiar strategy that worked well for them in previous learning and practice settings. Re-imagining the professional as well as personal opportunities that the RN role offered motivated and sustained them throughout their journey of developing independence. After working as an RN for 8 months, a participant reflected on the independence she had developed with the comment "I'm no longer in someone's shadow, no one is watching over my shoulder." As LPNs integrate the new knowledge, skills and attitudes they need to practice and develop as RNs, the heart of their learning is building up their independence.

\section{Conclusions}

The grounded theory of developing independence explains how learners progress to independence through resisting, reaching out and re-imagining. This grounded theory provides a glimpse into what nurses are doing to develop independence, highlighting what post-LPN to BN students and their teachers can expect in this transition. The grounded theory also provides insight into how this group of nurses resolve difficulties they encounter.

LPNs attending university initially demonstrate considerable resistance. Beneath the surface of this resistance is an enduring pride in an existing professional identity. As nurses already, it is what is different and new that is most important. As LPN to BN students reach out for the help they need, affirmation from others that they are "doing OK" is critically important. Knowing that these learners have made appreciable sacrifices, even selling homes or resigning from career jobs, the significance of others' affirmations, particularly those others who are in positions of determining student success or failure, becomes evident.

As the nurses have opportunities to actually practice as RNs, differences between the roles become apparent to them and they begin to re-imagine their profession and the possibilities for helping and leading that are now available. Central to all of these processes is moving away from being "in someone's shadow" and towards thinking and acting more independently.

While existing literature describes students' experiences at different points in time, the present research presents a deeper and more abstract theoretical explanation that may also resonate with learners who are not nurses. The theoretical explanation of the process nurses implement during their transition from LPN to BN and beyond generated through this study offers insights to educators developing curriculum and instruction. The theory is practical, relevant and fitting for a group of nurses who are continuing rather than beginning their professional education.

Acknowledgement: Funds for the program of research were awarded by the Social Sciences and Humanities Research Council of Canada; Western and Northern Region Canadian Association of Schools of Nursing Educational Innovation Award; and the Athabasca University Research Fund.

\section{References}

Boud, D. (Ed.). (1988). Developing student autonomy in learning. London: Kogan Page.

Brown, K. (2005). A case study of the first year of a new online RN from LPN program: Evaluation of program and student outcomes (Unpublished Ph.D. Dissertation). Central Michigan University, Mount Pleasant, MI
Claywell, L. (2003). The lived experience of licensed practical nurse $(L P N)$ to registered nurse (RN) transition (Unpublished Ph.D. Dissertation). University of Missouri, Saint Louis, MO.

Crabtree, H., Roberts, C., \& Tyler, C. (2007, September 13). Understanding the problems of transition into higher education. Paper presented at the Education in a Changing 
Environment ECE conference, University of Salford,

Manchester, UK.

Cree, V., Hounsell, J., Christie, H., McCune, V., \& Tett, L. (2009). From further education to higher education: Social Work students' experiences of transition to an ancient, research-led university. Social Work Education: The International Journal, 28(8), 887-901.

Cubit, K., \& Leeson, B. (2009). Is there a case for tailoring graduate programs for nurses who have previously practiced as enrolled nurses? Nurse Education Today, 29(8), 891-894.

Glaser, B. G. (1978). Theoretical sensitivity: Advances in the methodology of grounded theory. Mill Valley, CA: Sociology Press.

Glaser, B. G. (1992). Basics of grounded theory analysis: Emergence vs. forcing. Mill Valley, CA: Sociology Press.

Glaser, B. G. (1998). Doing grounded theory: Issues and discussions. Mill Valley, CA: Sociology Press.

Glaser, B. G. (2001). The grounded theory perspective: Conceptualization contrasted with description. Mill Valley, CA: Sociology Press.

Glaser, B. G. (2002). Constructivist grounded theory? Forum: Qualitative Social Research/Forum Qualitative Sozialforschung, 3(3)Art. 12. Retrieved from http://nbnresolvingde/urn:nbn: de:0114-fqs0203125

Glaser, B. G. (2007). All is data. The Grounded Theory Review, 6(2), 1-22. Retrieved from http://www.groundedtheoryreview.com/ documents/GTReviewvol6no2.pdf

Glaser, B. G., \& Strauss, A. L. (1967). The discovery of grounded theory: Strategies for qualitative research. Chicago, IL: Aldine Atherton.

Glaser, B. G., \& Holton, J. (2004). Remodeling grounded theory. Forum: Qualitative Social Research/Forum Qualitative Sozialforschung, 5(2), Article 4.

Gordon, K., \& Melrose, S. (2011a). LPN to BN nurses: Introducing a new group of potential health care leaders. e-Journal of Organizational Learning and Leadership, 9(1), 121-128.

Gordon, K., \& Melrose, S. (2011b). Peer e-mentoring podcasts in a selfpaced course. Academic Exchange Quarterly 15(3), 145-149.

Harris, A., \& McGillis Hall, L. (2012, March). Evidence to inform staff mix decision making: A focused literature review. Ottawa, ON, Canada: Canadian Nurses Association.

Hayward, G., Dunbar-Goddet, H., Ertl, H., \& Hoelscher, M. (2008, May). Degrees of success: Learners transition from vocational education and training to higher education. Research Briefing 42, Teaching and Learning Research Programme, London, UK.

Hoelscher, M., Hayward, G., Ertl, H., \& Dunbar-Goddet, H. (2008). The transition from vocational education and training to higher education: A successful pathway? Research Papers in Education, 23(2), 139-151. doi:10.1080/02671520802048679

Holec, H. (1981). Autonomy in foreign language learning. Oxford: Pergamon.

Hutchinson, L., Mitchell, C., \& St John, W. (2011). The transition experience of enrolled nurses to a bachelor of nursing at an Australian university. Contemporary Nurse, 38(1-2), 191-200.

Huynh, T. Alderson, M. Nadon, M., \& Kershaw-Rousseau, S. (2011). Voices that care: Licensed Practical nurses and the emotional labour underpinning their collaborative interactions with Registered Nurses. Nursing Research and Practice, Article ID 50179010 pages. doi:10.1155/2011/501790
Hylton, J. (2005). Relearning how to learn: Enrolled nurse transition to degree at a New Zealand rural satellite campus. Nurse Education Today, 25(7), 519-526. doi:10.1016/j. nedt.2005.05.010

Institutional Management in Higher Education (IMHE) (2012). The Cinderella of tertiary education: Post secondary vocational education and training. Imhe INFO Newsletter, May. Organisation for Economic Co-operation and Development OECD Forum on Higher Education Publications. Retrieved from http://www.oecd.org/edu/imhe/50305415.pdf

Karmel, T. (2011, April). As clear as mud: Defining vocational education and training. Paper presented at the 2011 TAFE Governance and Regulations Forum. Melbourne, Australia.

Kearney-Nunnery, R. (2010). Making the transition from LPN to RN. Davis: Philadelphia, PA.

Kilstof, K., \& Rochester, S. (2004). Hitting the ground running: Transitional experiences of graduates previously trained as enrolled nurses. Australian Journal of Advanced Nursing, 22(1), 13-17.

Knowles, M. S. (1975). Self-directed learning: A guide for learners and teachers. New York: Association Press.

Langworthy, A., \& Johns, S. (2012). Why is it important for higher education to connect with the VET sector?. In Brown, N., Jones S. M., and Adam, A. (Eds.), Higher Education Research and Development Society of Australia (HERDSA) (Vol. 35, pp 118-128). Hobart.

Little, D. (1991). Learner autonomy I: Definitions, issues and problems. Dublin: Authentik.

Melrose, S., \& Gordon, K. (2008). Online post LPN to BN students' views of transitioning to a new nursing role. International Journal of Nursing Education Scholarship, 5(1), Article 14. Retrieved from http://www.bepress.com/ijnes/vol5/iss1/art14

Melrose, S., \& Gordon, K. (2011). Overcoming barriers to role transition during an online Post LPN to BN program. Nurse Education in Practice, 11(1), 31-35.

Melrose, S., Miller, J., Gordon, K., \& Janzen, K. (2012). Becoming socialized into a new professional role: LPN to BN student nurses' experiences with legitimation. Nursing Research and Practice , Article ID 946063, 8 pages. doi:10.1155/2012/ 946063

Milligan, M. (2007). Enrolled nurses' experiences of conversion to first level (Unpublished EdD Dissertation). University of Stirling, Stirlingshire, Stirling.

Moodie, G. (2008). From vocational to higher education: An international perspective. New York, NY: Open University Press.

Nayda, R., \& Cheri, J. (2008). From enrolled nurse to registered nurse in the rural setting: The graduate nurse experience. Rural and Remote Health, 8, 900-908.

Rapley, P., Nathan, P., \& Davidson, L. (2006). EN to RN: The transition experience pre- and post-graduation. The International Electronic Journal of Rural and Remote Health Research, Education and Policy, 6(1), 1-13.

Vygotsky, L. S. (1978). Mind and society: The development of higher psychological processes. Cambridge, MA: Harvard University Press.

White, D., Oelke, N. D., Besner, J., Doran, D., McGillis Hall, L., \& Giovannetti, P. (2008). Nursing scope of practice: Descriptions and challenges. Nursing Leadership, 21(1), 45-57. 
